\title{
Assistência social: A política pública (inter)setorial
}

Thiago Prisco ${ }^{1}$

\footnotetext{
${ }^{1}$ Prefeitura Municipal de Contagem. Gestão do Acolhimento Institucional. Correspondência: E-mail: thiagoprisco@live.com Contagem - MG - Brasil
}

Resumo O estudo em tela apresenta o conceito de intersetorialidade, interpretando-o por meio da abordagem da administração pública e da saúde coletiva, como síntese e articulação, respectivamente. Desta forma, entendendo-a como um movimento de intersecção. Trata-se de um artigo de revisão bibliográfica, no qual são analisadas as definições de intersetorialidade, a relação que este fenômeno estabelece com a política pública de assistência social e apresenta de forma sucinta o Programa Bolsa Família, a título de exemplo do movimento de intersetorialidade entre as políticas públicas e a assistência social.

Palavras-chave: intersetorialidade, políticas públicas, assistência social, Programa Bolsa Família.

Abstract This study introduces the concept of screen intersectionality, interpreting it through the approach of public administration and public health, as synthesis and articulation, respectively. Thus, understanding it as a movement of intersection. This is a literature review, which is parsed definitions, intersectoral relationship that establishes this phenomenon with the public policy of social assistance and briefly presents the Programa Bolsa Família for an example of the movement of intersectionality between public politics and social assistance.

Keywords: intersectionality, public policy, social assistance, Program Bolsa Família.

Resumen El estudio presenta el concepto de intersectorialidad, interpretando por medio de la abordaje de la administración pública y de la salud pública, como síntesis y articulación, respectivamente. Así, comprende-se la intersectorialidad como un movimiento de intersección. Es un artículo de revisión bibliográfica, en que son analizadas las definiciones de intersectorialidad, la relación que el fenómeno establece con la política pública de asistencia social y 
presenta de forma sucinta el Programa Bolsa Família, como ejemplo del movimiento de intersectorialidad entre las políticas públicas y la asistencia social.

Palabras-clave: intersectorialidad, políticas públicas, asistencia social, Programa Bolsa Família. 


\section{Introdução}

Neste artigo, será analisado um dos princípios organizativos do Sistema Único de Assistência Social (SUAS), qual seja: a intersetorialidade das competências e ações entre o Sistema Único de Assistência Social e as demais políticas públicas, a quem também compete o exercício da proteção social.

Este pequeno estudo tem como pretensão apresentar o conceito de intersetorialidade e a relação dele com a política pública de assistência social, não apenas pela contemporaneidade do assunto, mas por ser um dos elementos essenciais para a operação desta política, além de apresentar a título de exemplo a integração entre as políticas sociais e a assistência social por meio do Programa Bolsa Família.

Entendendo as contribuições que emanam das distintas interpretações acerca da intersetorialidade, o tema será tratado a partir das contribuições da administração pública e da saúde coletiva, uma vez que ambas não são excludentes. Entretanto, é válido ressaltar, grosso modo, que a primeira a compreende como síntese e a segunda como articulação. Desta forma, neste texto entende-se o seu movimento tanto como um movimento de síntese como de articulação, redundando em um movimento de intersecção.

O estudo se deu por meio de revisão bibliográfica, a partir da contribuição de teóricos com reconhecimento neste campo de discussão e da observação e interpretação de textos normativos da assistência social no Brasil. Deste modo, na primeira parte do texto apresentaram-se algumas definições acerca da intersetorialidade, posteriormente estabeleceu-se a relação e o sentido deste fenômeno no Sistema Único de Assistência Social e, por fim, foi apresentado resumidamente o escopo do Programa Bolsa Família em seu movimento intersetorial. Além de algumas considerações para concluir o trabalho.

Não se objetiva por meio do presente texto esgotar as discussões sobre o fenômeno, todavia diante do exposto e do conteúdo expresso nas páginas seguintes, espera-se que este processo investigativo traga contribuições para o acervo do s e demais áreas afins das ciências sociais e possa suscitar algumas reflexões sobre o tema em questão.

Intersetorialidade: Em busca de teorias capazes de subsidiar a prática

Este tópico tem como objetivo apresentar e analisar conceituações sobre a intersetorialidade como uma categoria extremamente necessária para o sucesso na execução das políticas públicas, principalmente as de natureza social, visando 
o rompimento com o caráter verticalizador que elas têm apresentado durante a história política do Brasil.

Discorrendo sobre esta problemática, Yasbek et al. (2011:117) assegura que:

na organização societária brasileira, as políticas sociais se inscrevem na lógica de setorização que recorta o social em partes, demandando um processo de articulação que supere a tendência de compreender os problemas independentemente das causas estruturais que os originam.

Desta forma, crê-se que a intersetorialidade é responsável por este processo de articulação capaz de superar a tendência de buscar soluções para as expressões da questão social apenas na esfera da conjuntura, elevando o debate ao nível estrutural.

Como observa Pereira (2012:1), este é " um termo dotado de vários significados e possibilidades de aplicação prática", constituindo-se em "um conceito polissêmico" (2012:1), logo capaz de ser interpretado por diversos matizes conceituais.

Alguns teóricos, embasados na abordagem da administração pública e/ou da saúde coletiva, apresentam definições para a intersetorialidade. Como poderá ser evidenciado a seguir, é possível perceber a tendência a uma ou a outra abordagem pelos estudiosos do assunto. Com isso não se quer dizer que a opção por uma descarta a utilização da outra. No entanto, será apontada a que se revela mais clara na leitura das obras desses estudiosos.

Assim sendo, pode-se definir a abordagem dos autores em destaque neste estudo da seguinte forma:

(i) Abordagem da administração pública, a partir da literatura de Junqueira (2004), Inojosa (2001), Monnerat e Souza (2009), Pereira (2012), Nascimento (2010), Bronzo e Veiga (2007), Yazbek et al. (2011), Couto et al. (2011); e

(ii) (ii) Abordagem da saúde coletiva: Monnerat e Souza (2011).

Estes teóricos constroem em suas publicações concepções e descrições acerca da intersetorialidade que contribuem para a formulação de alguns enunciados apresentados no decorrer deste texto. 
Junqueira (2004:27) afirma que ela "é uma nova maneira de abordar os problemas sociais" e a entende como "um processo de aprendizagem e de determinação dos sujeitos" (2004:27).

Segundo Inojosa (2001:105), a intersetorialidade é “a articulação de saberes e experiências com vistas ao planejamento, para a realização e a avaliação de políticas, programas e projetos, com o objetivo de alcançar resultados sinérgicos em situações complexas".

Monnerat (2009:204) entende-a como "síntese de conhecimentos diversos (...) para atuar sobre problemas concretos" e "como uma articulação de ações de vários setores para alcançar melhores resultados" (Monnerat 2011:205).

Para Pereira (2012:1), a intersetorialidade é "uma nova lógica de gestão, que transcende um único 'setor' da política social, e estratégia política de articulação entre 'setores' sociais diversos e especializados".

A partir da interpretação de Nascimento (2010:99), a intersetorialidade formatase como a "integração de saberes e experiências sem prejuízo da setorialização e da autonomização".

Monnerat e Souza (2011:42) definem-na como:

construção de interfaces entre setores e instituições governamentais (e não governamentais), visando o enfrentamento de problemas sociais complexos que ultrapassem a alçada de um só setor de governo ou área de política pública.

Ainda definindo a intersetorialidade, Bronzo e Veiga (2007:12) afirmam que:

situa-se em um contínuo que abrangeria desde a articulação e coordenação de estruturas setoriais já existentes até uma gestão transversal, configurando formas intermediárias e arranjos organizativos que expressam a intersetorialidade de baixa ou alta densidade.

A partir da observação dos conceitos elencados acima, é possível entender a intersetorialidade como um movimento de intersecção. Optou-se por esta expressão, uma vez que ela indica um movimento conjunto de articulação e síntese que exige o esforço coordenado de diversos setores, significando mais do que uma simples troca ou soma de conhecimentos. 
A intersecção indica um movimento dialógico entre os múltiplos setores, por meio da criação de elos, com vistas a possibilitar a construção de uma instância capaz de abarcar homogeneamente as demais, sem com isso descaracterizá-las ou dissolvê-las.

Este argumento é corroborado por Junqueira ao evidenciar que:

a concretização da ação intersetorial incorpora não apenas a compreensão compartilhada sobre finalidades, objetivos, açôes e indicadores de cada programa ou projeto, mas práticas sociais articuladas que acarretem um impacto na qualidade de vida da população. Portanto, a viabilização dessa ação intersetorial depende da habilidade de criar grupos que possuam um senso compartilhado de realidade com coesão, em torno de entendimentos comuns, que determinam seu crescimento. (Junqueira 2004:27-28).

Deste modo, cada política pública permanece como um distinto setor, entretanto no seio do conjunto das diversas políticas a intersetorialidade ocupa-se de ser a matriz para o replanejamento das ações e servirá de conduto para o alcance das finalidades.

A intersetorialidade, por ser um fenômeno multidimensional, é entendida de diversas formas. Como infere Pereira (2012), ela é apresentada na bibliografia como: "articulação, soma, síntese, unidade, rede, superação da fragmentação". Além dessas expressões, é possível encontrar outras, tais como: integração, sinergia, modelo / estratégia / lógica de gestão, interface, inter-relação, entre outros.

O movimento de intersetorialidade permite o exercício de setorialidades mais competentes, uma vez que cada política pública pode desenhar o seu escopo de atuação setorialmente, redesenhá-lo intersetorialmente nas instâncias de debate e pactuação entre-setores e, novamente, realizar a sua aplicação setorialmente, entretanto obedecendo a uma lógica intersetorial. Desta forma, ocasiona um movimento cíclico que combina setorialidade e intersetorialidade, sendo ambos elementos indispensáveis para a implementação de políticas públicas de qualidade, eficientes e eficazes.

De acordo com a revisão da produção dos autores que subsidiam a escrita deste artigo, é corrente a percepção de que a escolha pela intersetorialidade não é condição sine qua non para o esgotamento da setorialidade, pelo contrário, há a ênfase acerca da necessidade de ambas ocorrerem simultaneamente.

Deste modo, Nascimento (2010) ressalta a importância de as políticas públicas serem planejadas setorialmente, entretanto baseadas na comunicação entre os distintos setores. Assim, "a intersetorialidade contribui para a criação e 
reconhecimento de saberes resultante da integração entre as áreas setoriais" (Nascimento 2010:101), tendo "como ponto de partida o respeito à diversidade e às particularidade de cada setor ou participante" (Yazbek et al. 2011:178).

Constitui-se em elemento indispensável para apresentar respostas às múltiplas expressões da questão social, uma vez que, como afirma Junqueira (2004), a realidade social é complexa e exige um olhar igualmente complexo, que uma única política social não é capaz de ter. Por esta razão, a intersetorialidade, ao considerar o cidadão em sua totalidade, pode superar a fragmentação setorial e inaugurar uma nova lógica de gestão.

Monnerat e Souza (2009), ao discorrer sobre as suas vantagens, reconhecem que seja capaz de minorar as questões relativas à fragmentação das políticas sociais, que fazem parte de uma construção histórica, em que "observa-se que há um grau de importância atribuída às políticas setoriais, pois atendem à conjuntura e à necessidade dos interesses em jogo, expressas no financiamento de cada uma delas" (Nascimento 2010:98). Além destas questões, a autora informa que outros entraves são postos ao movimento de efetivação da intersetorialidade entre as políticas sociais "por conta da própria cultura, dificuldades político-partidárias e outras questões que vão incidir sobre a execução das políticas" (Nascimento 2010:98).

Por esta razão, Bronzo e Veiga, asseveram possuir:

a conviç̧ão de que essa perspectiva não é algo natural ou que ocorra de forma espontânea nas organizações públicas, mas que tem que ser ativamente construída, uma vez que decorre de deliberações claras e compartilhadas para introduzir as mudanças nos processos de trabalho, no planejamento e na gestão das políticas públicas. (Bronzo e Veiga 2007:19).

Por conseguinte, com base nesta discussão é plausível reconhecer que a intersetorialidade possui algumas qualidades que podem contribuir para a formatação de um novo modo de planejar e executar as políticas sociais públicas, entre elas: (i) complementaridade entre os setores envolvidos; (ii) unificação das agendas dos diversos setores; (iii) intercâmbio de saberes, ações e incumbências; (iv) potencialização da capacidade executiva de cada setor/ator envolvido; (v) rompimento com a clausura; (vi) criação e manutenção de espaços dialógicos; (vii) enfrentamento e superação de dissensos; (viii) construção de consensos, (ix) conhecimento global da realidade que se pretende transformar.

Bronzo e Veiga reconhecem que: 
A perspectiva da intersetorialidade se materializa em diferentes âmbitos, no nível decisório, no campo dos arranjos institucionais e no das práticas operativas e metodologias de trabalho. Em todos os niveis o que se requer é a introdução de uma outra forma de apreender os problemas e de definir como atuar sobre eles, complementando a exigência da técnica e da especialização com as exigências de um olhar transversal sobre a realidade. (Bronzo e Veiga 2007:19).

Desta forma, faz-se possível apresentar três dimensões inerentes à intersetorialidade:

(i) Gerencial ou decisória: locus no qual as políticas públicas são formuladas, estruturadas e orçamentadas. É nele que a intersetorialidade pode ser introduzida como condição sine qua non para a implementação e execução destas políticas, como premissa indispensável e viabilizável nas demais instâncias de poder, no nível decisório.

(ii) Técnica: espaço privilegiado da ação profissional, no qual ocorre a execução das orientações advindas das instâncias superiores de poder, sendo ele o lugar essencialmente necessário para a materialização da intersetorialidade. Esta dimensão pode ser considerada teórico-prática, uma vez que além de viabilizar as pactuações emanadas do compromisso político de instâncias superiores, possibilita um (re)planejamento do que foi proposto na etapa anterior, como também nas seguintes.

(iii) Participativa ou popular: esta dimensão deve estar amalgamada às duas supracitadas. Não existe intersetorialidade que não tenha como objetivo privilegiar o usuário das políticas setoriais. É ele que tem a possibilidade, desde que instrumentalizado, para falar de suas necessidades, de modo a revelar os pontos não contemplados pelas políticas públicas. Deste modo, colabora com o mapeamento dessas ausências e pode ajudar a propor alternativas e estratégias para a efetividade de uma ação intersetorial, capaz de produzir respostas elegíveis que produzam impacto na realidade social.

Em suma, a intersetorialidade não é um fenômeno estanque, preso ao momento do planejamento ou da execução, é um elemento que deve estar dotado de intencionalidade e teleologia, uma vez que exige, "a articulação de saberes e experiências para a solução sinérgica de problemas complexos" (Inojosa 2001:103). Desta maneira, pode-se afirmar que as três dimensões estão em 
constante interação, em um fluxo dinâmico e articulado, sendo constantemente atualizado.

\section{A política social (inter)setorial}

A assistência social em 1988, por meio da Constituição Federal, foi elevada ao nível de política pública, como elemento constituinte do tripé da seguridade social juntamente com a saúde e a previdência social. Posteriormente, com a promulgação da Lei Orgânica da Assistência Social, que data de 1993, foram regulamentados os artigos 203 e 204 da Constituição Federal, dando maior legitimidade à assistência social como política social pública.

Conforme o Artigo 1 이 dei Orgânica da Assistência Social (LOAS), é "direito do cidadão e dever do Estado, é Política de Seguridade Social não contributiva, que provê os mínimos sociais, realizada através de um conjunto integrado de ações de iniciativa pública e da sociedade, para garantir o atendimento às necessidades básicas" (Brasil 1993).

Por isso, conforme explicitado no parágrafo único do Artigo 20 deve ser realizada "de forma integrada às políticas setoriais, visando ao enfrentamento da pobreza, à garantia dos mínimos sociais, ao provimento de condições para atender contingências sociais e à universalização dos direitos sociais" (Brasil 1993).

Com base em tais elementos a Política Nacional de Assistência Social (PNAS) assegura que:

a Assistência Social (...) deve fundamentalmente inserir-se na articulação intersetorial com outras políticas sociais, particularmente, as públicas de Saúde, Educação, Cultura, Esporte, Emprego, Habitação, entre outras, para que as ações não sejam fragmentadas e se mantenha o acesso e a qualidade dos serviços para todas as famílias e indivíduos. (Brasil 2004:42).

A Norma Operacional Básica do Sistema Único de Assistência Social (NOB/SUAS), ao elencar os princípios organizativos do sistema, propõe a articulação de competências e ações entre o Sistema Único de Assistência Social e outros sistemas, entre eles: Sistema Único de Saúde, Sistema Nacional de Previdência Social, Sistema Nacional e Estadual de Justiça e Sistema Educacional (Brasil 2005:88).

Especificando o campo de atuação da assistência social, o Artigo $2^{\circ}$ da LOAS reza que ela tem por objetivo: 
a proteção à famillia, à maternidade, à infância, à adolescência e à velhice; o amparo às crianças e adolescentes carentes; a promoção da integração ao mercado de trabalho; a habilitação e reabilitação das pessoas portadoras de deficiência e a promoção de sua integração à vida comunitária; a garantia de 1 (um) salário mínimo de benefício mensal à pessoa portadora de deficiência e ao idoso que comprovem não possuir meios de prover a própria manutenção ou de tê-la provida por sua familia (Brasil 1993).

Tais objetivos exigem que esta política atue de forma intersetorial, uma vez que todos eles demandam esforços plurais por se tratarem de questões complexas, que são perpassadas pelas várias expressões da questão social. Assim sendo, “o próprio objeto de intervenção da assistência social, marcado por demandas multifacetadas, exige respostas que extrapolam a repartição setorial" (Monnerat e Souza 2011:47). Sendo esta a razão de apresentar "a ação intersetorial como princípio norteador de seus programas sociais" (Monnerat e Souza 2009:202203).

Todavia, é necessário salientar que a PNAS reconhece a política de assistência social tanto como setorial quanto como intersetorial, uma vez que informa que ela "tem seu campo próprio de atuação e que se realiza em estreita relação com outras políticas" (Brasil 2004:54).

Por esta razão Monnerat e Souza (2009) afirmam que a intersetorialidade faz parte do desenho do Sistema único de Assistência Social (SUAS) e, consequentemente, está mais difundido na política de assistência social que nos demais programas do Ministério do Desenvolvimento Social, conquanto "a preocupação com a promoção da intersetorialidade está expressa em todos os programas do MDS [ Ministério do Desenvolvimento Social e Combate à Fome]" (Monnerat e Souza 2009:206).

Sobre essa discussão Monnerat e Souza (2011:46) problematizam que:

Embora a assistência social, dentre as áreas que compõem o tripé da Seguridade Social, seja a que tenha maior clareza política acerca da importância de se estabelecer estratégias de atuação intersetorial (e isto está presente nos documentos oficiais e no desenho da própria política), a capacidade institucional, financeira e política desta arena setorial ainda é muito baixa. (Monnerat e Souza 2011:46). 
De acordo com Yazbek et al. (2011:178), o movimento intersetorial inerente à política de assistência social deve objetivar a construção da proteção social, com vistas a construir uma rede socioassistencial, capaz de articular com as iniciativas públicas estatais e delas com a sociedade civil organizada. Por conseguinte:

deve expressar a articulação entre as políticas públicas, por meio do desenvolvimento de ações conjuntas destinadas à proteção social básica ou especial e ao enfrentamento das desigualdades sociais identificadas nas distintas áreas (Couto et al. 2011:39).

Sendo assim, é justo reconhecer que o enfrentamento das múltiplas expressões da questão social só pode ocorrer mediante a reunião de esforços e investimentos das diversas políticas públicas, por meio de um movimento constante de redesenho coletivo das ações setoriais com a ampliação da capacidade orçamentária, que consequentemente, resultarão em ações intersetoriais.

\section{A título de exemplo}

Um dos programas do MDS que manifesta a intersetorialidade com clareza é o Programa Bolsa Família, que de acordo com Monnerat e Souza (2011:46):

traz expressa a preocupação em dar um passo adiante no enfrentamento da fragmentação da intervenção do Estado na área social". Conforme, observam as autoras supracitadas "até hoje nenhum outro programa social foi tão dependente da articulação intersetorial e, portanto, das capacidades institucionais e de diálogo político entre os entes da federação e os diferentes setores responsáveis pelo desenvolvimento das políticas sociais (2011:46).

O programa foi criado por meio da medida provisória 132 de outubro de 2003 que, posteriormente, foi convertida na Lei 10.836 de 09 de janeiro de 2004, sob a gestão do Ministério do Desenvolvimento Social e Combate à Fome (MDS). Desta forma, objetiva: 
contribuir para a superação da pobreza, especialmente no grau mais extremo. São três eixos principais de atuação: Diminuição imediata da pobreza, por meio da transferência direta de renda às famílias; Reforço do direito de acesso das familias aos serviços básicos nas áreas de saúde, educação e assistência social, por meio das condicionalidades, o que contribui para as familias romperem o ciclo da pobreza entre geraçóes; Integração com outras ações e programas dos governos, nas suas três esferas, e da sociedade para apoiar as familias a superarem a situação de vulnerabilidade e pobreza (Brasil 2013:3).

Conforme é possível evidenciar, o objetivo central do programa, contribuir para a superação da pobreza, é um desafio impossível de ser alcançado pela atuação de uma única política pública, o que, consequentemente, requer a ação de diversas políticas públicas em um movimento dialógico, coordenado e planejado.

O Programa Bolsa Família impõe algumas condicionalidades para as famílias e para o poder público a fim de proporcionar o acesso dos cidadãos às políticas públicas e "identificar os motivos que impedem o acesso das familias aos serviços sociais básicos" (Brasil 2013:8). Assim, "o objetivo das condicionalidades é assegurar o acesso dos beneficiários às políticas sociais básicas de saúde, educação e assistência social" (Brasil 2008).

Deste modo, para as famílias as condicionalidades estão divididas inicialmente no escopo de três políticas públicas (Brasil 2009):

(i) Saúde:

a. Crianças menores de sete anos: acompanhar o calendário de vacinação, o crescimento e desenvolvimento;

b. Gestantes e nutrizes: as primeiras deverão realizar pré-natal e as segundas acompanhamento.

(ii) Educação:

a. Crianças e adolescentes entre 6 e 15 anos: realizar matrícula e monitorar frequência escolar mensal mínima de 85\%;

b. Adolescentes entre 16 e 17 anos: matrícula e frequência escolar mensal mínima de $75 \%$.

c. Assistência Social: crianças e adolescentes menores de 16 anos em situação de trabalho infantil devem manter frequência de $85 \%$ nos Serviços de Convivência e Fortalecimento de Vínculos do Programa de 
Erradicação do Trabalho Infantil (PETI). Além do acompanhamento das condicionalidades por meio do Programa de Atenção à Família (PAIF), ofertado nos Centros de Referência em Assistência Social (CRAS).

Por conseguinte, ao poder público compete a oferta dos serviços, o acompanhamento e a fiscalização do cumprimento das condicionalidades, por meio das políticas supracitadas, sendo que à assistência social compete também a coordenação das ações.

Além dos compromissos assumidos pelo poder público e pelas famílias, o Programa Bolsa Família:

também busca a integração com outras políticas públicas, como ações de qualificação profissional e de apoio à geração de trabalho e renda, de alfabetização e educação para jovens e adultos, de melhoria do acesso à moradia, dentre outros (Brasil 2008:6).

As ações complementares deste programa também apresentam interface com o Ministério do Trabalho e Emprego, por meio da oferta do Programa Nacional de Microcrédito Produtivo Orientado; Plano Setorial de Qualificação Profissional para os Beneficiários do Programa Bolsa Família; Projeto de Promoção do Desenvolvimento Local e Economia Solidária; e com o Ministério do Desenvolvimento Agrário, através do Programa Territórios da Cidadania (Brasil 2008).

Como é possível observar, para que este programa logre êxito é fundamental que a intersetorialidade faça parte de sua matriz tanto teórica quanto prática. Isso ocorre principalmente porque o programa objetiva dar respostas a uma das mais complexas expressões da questão social, a pobreza, que pode ser entendida como fruto da distribuição desigual da riqueza socialmente produzida, e que, consequentemente, só terá fim com o término deste modelo econômico e social. Todavia, faz-se necessário procurar alternativas capazes de minorar os rebatimentos ocasionados por ela, e a intersetorialidade se coloca como um meio plausível para isso.

Apesar de não parecer reconhecer nos documentos oficiais a pobreza como um fenômeno estrutural à sociedade capitalista, sem chances reais de ser solucionada enquanto este modo de produção perdurar, fundamental é assumir que com vistas a atingir o objetivo central, o Programa Bolsa Família, por meio das condicionalidades, reconhece ser a pobreza um fenômeno multidimensional e convoca diversas políticas públicas a enfrentá-la como tal. 
Desta forma, por meio da coordenação da assistência social, gera intersecções com as políticas de educação e saúde para realizar as ações centrais do programa. E para as complementares convoca as demais políticas setoriais, imprimindo a lógica intersetorial tanto ao programa quanto às políticas sociais públicas envolvidas no processo ao viabilizar a sua operação.

\section{Considerações finais}

Conforme foi proposto neste artigo, discutiu-se sobre o conceito de intersetorialidade, a presença deste fenômeno na política de assistência social e utilizou-se o Programa Bolsa Família como uma amostra do exercício dela entre as políticas setoriais, inclusive na assistência.

A partir da observação e análise dos conceitos, faz-se possível inferir que a intersetorialidade não é apenas um movimento de articulação entre as políticas setoriais, nem tão somente a síntese de suas ações, e, sim, a intersecção entre elas.

Logo, a ação intersetorial é um movimento que preserva a setorização, mas que inova ao permitir que diversos olhares e metodologias sejam compartilhadas e pactuadas, com vistas a fundar uma ação coletiva e cooperativa no enfrentamento das expressões da questão social.

Sendo assim, não se trata apenas de discutir "o que fazer" no âmbito das políticas, mas "como fazer", e isto está extremamente relacionado ao processo de trabalho, que por sua vez perpassa por questões de natureza política, institucional, cultural, etc.

Neste cenário, a assistência social encontra a vantagem de ser uma política pública que tem impressa em sua matriz a lógica intersetorial. Todavia, isso não quer dizer que na prática ela sempre atuará desta forma, pois a ação intersetorial exige uma relação entre teoria e prática constante e exaustiva. Não adianta nada pactuar e normatizar a intersetorialidade, e aqueles que estiverem na ponta optarem por desconsiderar este caráter fundamental da política e a executar setorialmente.

Faz-se urgente reconhecer que se a assistência social opta por trabalhar isoladamente, está decretando a ineficácia de suas ações e, consequentemente, se estabelecendo como uma política assistencialista, uma vez que não será capaz de superar ações meramente pontuais e emergenciais.

Não porque seja uma política pública incompleta, mas por possuir objetivos complexos e se colocar na atualidade como uma política estruturadora, exigindo assim que as demais contribuam com a sua operacionalização. 
Como exemplo deste caráter estruturador, que supõe ações intersetoriais, têmse o Programa de Erradicação do Trabalho Infantil (PETI) e o Programa Bolsa Família, citado a título de exemplo no corpo deste texto, ambos sob a coordenação da assistência social.

Todavia, apesar da existência desses programas, dos avanços e da adesão indiscutível à intersetorialidade pela política pública de assistência social, ainda há muito que construir sobre este tema.

\section{Referências}

Brasil. Acompanhamento familiar: Programa Bolsa Famillia. Brasília: Ministério do Desenvolvimento Social e Combate à Fome, 2009. Disponível na internet em: http://www.mds.gov.br/biblioteca [ Acesso em jan. 2013].

Brasil. Bolsa Família: Transferência de renda e apoio à família no acesso à saúde e à educação. Brasília: Ministério do Desenvolvimento Social e Combate à Fome, 2013. Disponível na internet em: http://www.mds.gov.br/biblioteca [ Acesso em jan. 2013].

Brasil. Guia de Atuação das Instâncias de Controle Social (ICS). 2a. ed. Brasília: Ministério do Desenvolvimento Social e Combate à Fome, 2008. Disponível na internet em: http://www.mds.gov.br/biblioteca [ Acesso em jan. 2013].

Brasil. Ministério do Desenvolvimento Social e Combate à Fome. Norma Operacional Básica NOB/SUAS. Brasília, 2005.

Brasil. Ministério do Desenvolvimento Social e Combate à Fome. Política Nacional de Assistência Social PNAS. Brasília, 2004.

Bronzo C, Veiga L. Intersetorialidade e políticas de superação da pobreza: Desafios para a prática. Serviço Social \& Sociedade 2007, 92:5-21.

Couto BR, Yasbek MC, Raichelis R. A Política Nacional de Assistência Social e o SUAS: Apresentando e problematizando fundamentos e conceitos. In: Couto BR, Yasbek MC, Silva MOS, Raichelis R (Orgs.). O Sistema Único de Assistência Social no Brasil: Uma realidade em movimento. 2a. ed. São Paulo: Cortez Editora, 2011.

Inojosa RM. Sinergia em políticas e serviços públicos: Desenvolvimento social com intersetorialidade. Cadernos FUNDAP 2001, 22:102-110.

Junqueira LAP. A gestão intersetorial das políticas sociais e o terceiro setor. Saúde e Sociedade 2004, 13(1):25-36. 
Monnerat GL, Souza RG. Da seguridade social à intersetorialidade: Reflexões sobre a integração das políticas sociais no Brasil. Revista Katályses 2011, 14(1):41-49.

Monnerat GL, Souza RG. Política social e intersetorialidade: Consensos teóricos e desafios práticos. SER Social2009, 12(26):200-220.

Nascimento S. Reflexões sobre a intersetorialidade entre as políticas públicas. Serviço Social e Sociedade 2010, 101:95-120.

Pereira PAP. A intersetorialidade das políticas sociais numa perspectiva dialética. Disponível na internet em: http://matriz.sipia.gov.br/ images/acervo/Texto\%20 Potyara\%20-\%20intersetorialidade.pdf [ Acesso em dez. 2012].

Yazbek MC, Mestriner ML, Chiachio NB, Raichelis R, Paz R, Nery VB. O Sistema Único de Assistência Social em São Paulo e Minas Gerais: Desafios e perspectivas de uma realidade em movimento In: Couto BR, Yasbek MC, Silva MOS, Raichelis R (Orgs.). O Sistema Único de Assistência Social no Brasil: Uma realidade em movimento. 2a. ed. São Paulo: Cortez Editora, 2011. 